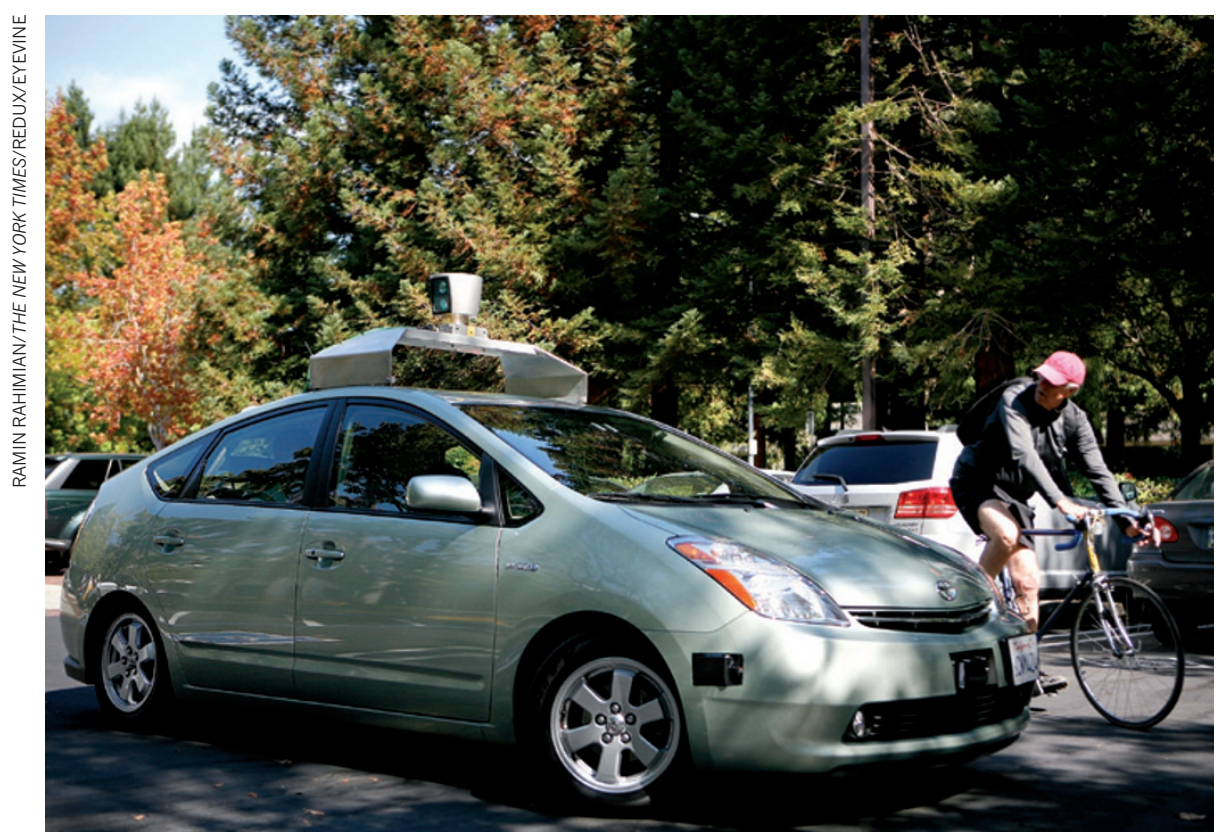

Google's self-driving car senses nearby objects to mimic the decisions of a human driver.

\section{A vision of our transport future}

\section{Lawrence D. Burns explains how networks of driverless, shared cars will revolutionize motoring.}

\section{$\mathrm{W}$}

hen I was named vice-president of research and development at General Motors (GM) in 1998, I was asked: "If we reinvented the automobile, what would be different?" This question has framed my work since.

Today, around a billion cars and trucks move people and goods on the world's roads. Parked end-to-end, this fleet would circle Earth more than 100 times. It is remarkable that such scale has been achieved with little change to the machine that was invented by Karl Benz and popularized by Henry Ford more than a century ago. The basic design of automobiles today is the same as it was in 1900: energized by oil, powered by combustion, driven mechanically by a person and intended for broad purpose.

Yet road transportation as we know it is unsustainable. More than 1.2 million people die on the road each year, equivalent to an epidemic, according to the World Health Organization. Ninety-five per cent of motor vehicles depend on oil for energy, holding car travel hostage to geopolitical issues and volatility in oil prices. Vehicle combustion engines account for more than one-fifth of the world's carbon dioxide emissions, making them a significant contributor to global climate change.
And average speeds in congested cities can be as low as 20 kilometres per hour, causing productivity losses and travel stress.

The road transport system has remained stable because of its complexity. With a mix of public and private elements, the motor industry has strong vested interests and ingrained business models. People and businesses derive value from all parts of the system working together - vehicles, roads, fuel stations, traffic laws, regulations, vehicle standards and trained drivers.

So overcoming the problems requires rethinking the entire system. It is not enough to focus on better batteries or fuel economy or the automobile industry alone. The solution must meet the needs of all users, including business. Fortunately, the technology now exists to build an integrated network of driverless, electrical vehicles that are connected, coordinated and shared.

Consider a typical car owner, Joe, living in a medium-sized city such as Ann Arbor, Michigan. Joe drives his car about 50 kilometres a day at a cost of around US\$0.40 per kilometre, which includes depreciation, insurance, fuel,

\section{DNATURE.COM}

More on small electric vehicles:

go.nature.com/azklzq maintenance, licence fees, finance charges and taxes. Parking costs more, and he spends more than an hour each day driving to work, shops and schools.

Now imagine a different scenario. Joe requests a car using a smartphone application. A driverless electric vehicle arrives within minutes and transports him to his destination. During the trip, Joe can read, work, eat, talk on the phone, watch a film or send e-mails. There is no need to park - the vehicle zooms off to pick up another rider.

Joe concludes that he no longer needs to own a car. His trips are safe, timely and convenient. He can use his travel time productively. The price and mode of payment are attractive - his account is automatically debited for each journey. And Joe appreciates that electric vehicles create fewer emissions than his petrol-powered car. His enthusiasm stems not from any one technology, but from a combination of satisfactory experiences.

\section{BUILDING BLOCKS}

Can this dream be realized? I think so - the building blocks already exist.

Connected vehicles. These communicate with surrounding vehicles and infrastructure through the digital 'cloud' to enable hands-free calling, navigation, emergency response and concierge services. They have matured rapidly since the first Global Positioning System unit appeared in a personal car in 1995: products such as GM's OnStar and Ford's SYNC are already installed in tens of millions of cars. Logistics companies such as FedEx and UPS use vehicle connectivity to enhance fleet operations.

Coordinated vehicles. These choreograph the movement of people and goods just as the Internet manages streams of information. Real-time data optimize traffic flow and parking ${ }^{1}$. Most large cities already provide traffic information to help drivers avoid bottlenecks. And California is testing smart parking systems, such as SFpark and LA Express Park, that allow drivers to use mobile apps to check parking availability and pricing.

Shared vehicles. These serve several people throughout a day, in contrast to personally owned vehicles that are parked 90\% of the time. More than 25 shared-vehicle companies already exist, such as Zipcar, Uber and RelayRides in the United States, Buzzcar in France and Car2Go in Germany. As of December 2012, there were 1.7 million car-sharing members in 27 countries, according to the Transportation Sustainability Research Center at the University of California, Berkeley. It is estimated that, by 2016, vehicle-sharing revenue will exceed $\$ 3$ billion in North America ${ }^{2}$.

Driverless vehicles. The companies developing these - Google, Daimler, Volvo, GM, Toyota, Volkswagen, BMW, Bosch, 
> Continental and Delphi - claim that they will have proven technology by 2020 or sooner. Google, for example, has a fleet of Toyota Prius and Lexus vehicles that has already driven some 800,000 kilometres on public roads. Driverless vehicles respond to others nearby to evade crashes and free up drivers' time. Because these cars are less prone to crashing, they need fewer safety features and can therefore be smaller and lighter than current vehicles, making them better suited to electric power.

Much work remains to be done to convince consumers and regulators that driverless vehicles are safer than human-driven ones in all circumstances, such as mixed traffic, snow-covered roads and construction zones. But the rise in computer processing power, better sensors made possible by nanotechnology and improved algorithms stemming from 'big data' analytics will, in my view, continue to accelerate progress.

Electrical vehicles. These are powered by electric motors and have digital controls to diversify sources of energy, reduce emissions and improve efficiency. They include hybrids, such as the Toyota Prius; plug-in electric or hybrid cars, such as the Nissan Leaf, Chevrolet Volt and Tesla Model S; and fuel-cell vehicles, such as the Hyundai ix35. After 15 years on the market, hybrids are now approaching a $4 \%$ share of new car sales in the United States.

Although the use of lithium-ion batteries has improved plug-in electric vehicles, their popularity is still limited by range, recharging time and cost. Further battery breakthroughs and reductions in vehicle weight will be required if plug-in cars are to have as wide appeal as conventional-sized cars. And although Hyundai, Daimler, Ford, Nissan, Toyota and Honda have all announced commercial plans to launch hydrogen fuel-cell electrical vehicles in the next five years, the development of a hydrogen-refuelling infrastructure remains a challenge.

Tailored vehicles. These are designed for specific types of mobility and numbers of occupants, making them more energy-, space- and cost-efficient than most cars, which are often overspecified for their typical use. For example, $90 \%$ of US car journeys carry one or two people ${ }^{3}$, but most vehicles have four or more seats. And whereas cars can travel at speeds of more than 160 kilometres an hour, average speeds in cities are less than 50 kilometres per hour.

In response to growing urbanization, tailored vehicles have become a dominant theme at global car shows. A 2012 report $^{4}$ concluded that 150 varieties of one- and two-passenger vehicles could exist by 2020 . At one-third of the weight of typical cars, tailored vehicles can go much farther on smaller batteries, making them better suited to being plug-in cars.

Together, these building blocks can bring radical improvements. How will the costs and benefits compare with the status quo? In 2010, I teamed up with economist Jeffrey Sachs at Columbia University's Earth Institute in New York to establish the Program on Sustainable Mobility and to assess the potential of driverless electrical vehicle systems for various locations.

For a citizen of a city like Ann Arbor, such a service could be more than $70 \%$ cheaper and would require residents to invest less than one-fifth of the amount needed to own their cars ${ }^{5}$. About $80 \%$ fewer shared, coordinated vehicles would be needed than personally owned vehicles to provide the same level of mobility, with less investment.

And there are other benefits. Lightweight, two-passenger vehicles are ten times more energy efficient than a typical car. Driverless, shared vehicles free up time that people currently spend driving and parking. For example, at the US minimum wage of $\$ 7.25$ per hour, travelling costs $\$ 0.15$ per kilometre at a speed of 50 kilometres per hour, or $\$ 0.50$ per

\section{"We must bring together technology, systems design and business models to supply better mobility."} kilometre at the US median income of $\$ 25$ per hour. Americans drive almost 5 trillion kilometres per year, so saving even just 1 cent per kilometre by freeing up people's time accrues $\$ 50$ billion per year.

Connected and driverless vehicles that avoid crashes mean fewer deaths and injuries and less property damage. Vehicles in shared fleets reduce the need for car parks. Smoother traffic flow and lighter vehicles reduce emissions and congestion.

\section{NEXT STEPS}

Not everyone is as excited by my vision as I am. Many people like to drive, and do not like to share their cars. Others think that we should instead invest in public transport, such as trains, trams, buses and cycle-lease systems, which, although heavily subsidized, already impart some of the benefits described above. Still others question whether the reliability and security of computer networks can deliver safe driverless travel. And those with vested interests in today's road-transport system might resist substantial changes. But even though connected, coordinated, shared and driverless vehicles are not the only option, I see them as one mode of travel that should be explored. The market will ultimately determine whether this model can succeed.

Technology is no longer the biggest hurdle. We need to create the collective will to move forward. Prototypes need to be deployed in representative communities so that we can learn what works. Such learning cycles are essential to prove what is possible, to identify what consumers like and dislike, to determine which business models are attractive and to avoid unintended consequences.

California, Florida and Nevada already allow prototype self-driven vehicles to be used on public roads. In Ann Arbor, the University of Michigan Transportation Research Institute is conducting a connected vehicle safety pilot with more than 3,000 drivers, sponsored by the US Department of Transportation. This is the world's first opportunity to assess the safety benefits and reliability of connected vehicle systems on real roads. The university is launching a mobility transformation centre, to develop and test innovative prototype systems based on connected, coordinated, shared, driverless and tailored vehicles.

Once proven and regulated, prototype systems should scale quickly without public incentives. Policy-makers can allow this innovation to play out safely. As with other new products that converged on a market tipping point - such as mobile phones, electronic books, digital photography and music formats, and flat-screen televisions - economic forces will naturally lead to large-scale deployment when consumers want to use a product because its value exceeds what they pay, and businesses want to supply it because their revenue exceeds their cost.

Sustainable mobility is a team sport. We must bring together technology, systemsdesign methods and business models to supply better mobility at a low cost to consumers and to societies. After 15 years of striving to reinvent the automobile, the question that now frames my work is: "How do we achieve what is possible?"

Lawrence D. Burns is professor of engineering practice at the University of Michigan, Ann Arbor, Michigan, USA, and directs the Program on Sustainable Mobility at the Earth Institute, Columbia University, New York, USA. He was corporate vicepresident of research and development and planning at General Motors until 2009. e-mail:lawrencedburns@gmail.com

1. Mitchell, W. J., Borroni-Bird, C. E. \& Burns, L. D. Reinventing the Automobile: Personal Mobility for the 21st Century (MIT Press, 2010).

2. Sacks, D. 'The Sharing Economy' Fast Company (18 April 2011); available at http://go.nature. com/co6pte.

3. Summary of Travel Trends: 2009 National Household Travel Survey (US Department of Transportation Federal Highway Administration, 2011).

4. Shankar, V. Strategic Analysis and Benchmarking of Global OEMs Micro-Mobility Solutions (Frost \& Sullivan, 2012).

5. Burns, L. D., Jordan, W. C. \& Scarborough, B. A Transforming Personal Mobility (Earth Institute, Columbia University, 2013).

The author declares competing financial interests: see go.nature.com/eb9bu3 for details. 